\title{
AVANÇOS NA BANANICULTURA BRASILEIRA ${ }^{1}$
}

\author{
LUIZ ALBERTO LICHTEMBERG ${ }^{2} \&$ PAULO DOS SANTOS FARIA LICHTEMBERG ${ }^{3}$
}

RESUMO - A bananicultura brasileira passou por transformação a partir do início do século passado, com o início das exportações do litoral paulista para o mercado platino e europeu. Ações da Secretaria da Agricultura de São Paulo permitiram uma mudança do simples semi-extrativismo para uma bananicultura com uso de técnicas agronômicas de manejo cultural, adubação e fitossanidade. A partir da década de 50, o Instituto Agronômico e o Instituto Biológico de São Paulo intensificaram as pesquisas com o cultivo da bananeira. Na década de 70, com a criação da Sociedade Brasileira de Fruticultura e do Sistema Embrapa de Pesquisa, os progressos alcançados pelo Centro Nacional de Pesquisa de Mandioca e Fruticultura, pelas empresas estaduais e institutos de pesquisa agropecuária de todo o País e pelas universidades, permitiram a prática de uma bananicultura mais evoluída. Além disso, a assistência técnica oficial e privada, empreendimentos privados e a criação de projetos de irrigação no semiárido brasileiro permitiram a ampliação da área de cultivo da bananeira em bases tecnológicas mais evoluídas. Nas duas últimas décadas, floresceram as organizações de bananicultores que, através de seus técnicos, promovem a melhoria tecnológica do cultivo. Neste trabalho, são apresentados dados estatísticos e descritas técnicas de cultivo atualmente disponíveis para a bananicultura brasileira, destacando-se a criação e a seleção de novos genótipos, técnicas de produção de mudas, práticas culturais de manejo em pré e pós-colheita, controle de pragas e doenças, e sistemas alternativos de cultivo. Termos para indexação: banana, dados estatísticos, melhoramento genético, práticas culturais, manejo pós-colheita, doenças.

\section{ADVANCES ON THE BRAZILIAN BANANA CROP}

\begin{abstract}
Since the beginning of the last century the Brazilian banana crop pass by a transformation generated by the export trade from the coast of Sao Paulo State to the Latin and European market. Achievements from the Agriculture Department of Sao Paulo State allowed changes from the semi-extraction system for a modern banana production, involving practices such as: crop and fertilization management and also disease and plagues control. In the 1950's the Agronomic Institute (Instituto Agronômico) and the Biological Institute (Instituto Biológico), both from Sao Paulo State increased the banana crop research. On the 1970's with the establishment of the Fruit-Crops Brazilian Society (Sociedade rasileira e Fruticultura), Embrapa Research, and the progress attained by the National Research Center of Cassava and Fruit-crops (Centro Nacional de Pesquisa de Mandioca e Fruticultura), the several State Research Centers and the universities permit important improvements for the national banana production. Moreover, the official and private extension services, the private corporations and the irrigation projects at the Brazilian semi-arid, increased significantly the banana cultivation areas using most technological methodologies. The two last decades the number of grower associations raised, and with better organization they implemented and improved the available technologies with technician support. On this paper statistical data and crop techniques available for the Brazilian banana crop are described with emphasis on the selection of new genotypes. Good agricultural practices such as seedling, pre- and pos-harvesting management, plant protection strategies and alternative cultivation systems are also demonstrated.
\end{abstract}

Index Terms: banana, statistical data, genetic improvement, cultural practices, post harvest management, diseases.

\footnotetext{
${ }^{1}$ Palestra Sinfruit 214 - Simpósio Internacional de Fruticultura - Avanços na Fruticultura (17 a 21 Outubro)

${ }^{2}$ Engenheiro Agrônomo, MSc em Agronomia, pesquisador da Epagri, Caixa Postal 277, CEP 88301-970, Itajaí-SC.

E-mail: licht@epagri.sc.gov.br

${ }^{3}$ Engenheiro Agrônomo, MSc em Gerenciamento de Recursos Naturais, bolsista da Universidade da Califórnia -

Davis. E-mail: lichtemberg@gmail.com
} 


\section{INTRODUÇ̃̃O}

Segundo informações citadas por Moreira e Cordeiro (2006), a banana já era cultivada pelas populações indígenas do Brasil à época do seu descobrimento, existindo aqui, pelo menos, duas variedades da fruta, provavelmente a 'Branca' e a 'Pacova'. Daquela época até o início do século passado, o cultivo era semiextrativista, consistindo praticamente em práticas de plantio, em algumas roçadas e em colheita. Com o início das exportações de bananas dos Estados do Rio de Janeiro, São Paulo, Paraná e Santa Catarina, para o mercado platino, a partir de 1904 (MOREIRA; CORDEIRO, 2006), a bananicultura brasileira passou por transformação a partir do início do século passado. A partir de 1912, a maior parte das exportações brasileiras da fruta já era feita através do porto de Santos, o que fez com que a Secretaria da Agricultura, Indústria e Comércio do Estado de São Paulo passasse a investir na geração de tecnologia para este cultivo (SCHMIDT, 1934). Segundo Moreira e Cordeiro (2006), os primeiros experimentos foram instalados em 1925, pelo Instituto Agronômico de Campinas (IAC), e depois pelo Instituto Biológico de São Paulo (IB), seguidos pelas avaliações do Instituto de Economia Agrícola (IAA) e dos trabalhos feitos pelo Instituto de Tecnologia Agrícola (ITAL). Em 18-05-1931, o Horto Tropical de Ubatuba, no litoral paulista, foi transformado em Campo Experimental da Cultura de Bananeiras, subordinado à Diretoria de Inspeção e Fomento Agrícolas da Secretaria da Agricultura, e, três anos depois, já contava com uma coleção de cultivares de bananeira e realizava estudos sobre métodos de acondicionamento e conservação dos frutos para o transporte aos mercados estrangeiros (SCHMIDT, 1934). Em 1934, era publicado um livro intitulado "A cultura prática da Bananeira Nanica no Litoral Norte Paulista" (SCHMIDT, 1934), com considerações sobre botânica, edafologia, climatologia e variedades, e com recomendações técnicas de plantio, tratos culturais, adubação, controle de pragas e doenças, colheita e transporte da fruta, o que já permitia a mudança do simples semiextrativismo para uma bananicultura com uso de técnicas agronômicas de manejo cultural, adubação e fitossanitárias. A partir da década de 1950, o Instituto Agronômico e o Instituto Biológico de São Paulo intensificaram as pesquisas com o cultivo da bananeira, cujos resultados propiciaram bases para o começo das investigações feitas depois de 1970, por instituições de outros estados, e para instruções práticas para produtores de todo o País. A partir da década de 1970, com a criação da Sociedade Brasileira de Fruticultura e do Sistema Embrapa de Pesquisa, os progressos alcançados pelo Centro Nacional de Pesquisa de Mandioca e Fruticultura, pelas empresas estaduais e institutos de pesquisa agropecuária de todo o País e pelas universidades, permitiram a prática de uma bananicultura mais avançada. Nas décadas de 1970 e 1980, os pesquisadores Raul Soares Moreira, do Instituto Agronômico, e João Adelino Martinez, do Instituto Biológico, ministraram diversos cursos sobre bananicultura, em todas as regiões do Brasil, difundindo a tecnologia disponível na época. Nas décadas de 1980 e de 1990, a Cooperativa Cotia desenvolveu um importante trabalho na melhoria da qualidade da fruta do Vale do Ribeira exportada para o mercado platino. Além disso, a assistência técnica oficial e privada dos diversos estados produtores, os empreendimentos privados e a criação de projetos de irrigação no semiárido brasileiro permitiram a ampliação da área de cultivo da bananeira e do uso da tecnologia gerada. A publicação dos livros "Banana: Teoria e Prática de Cultivo" (MOREIRA, 1987) e "A cultura da banana: aspectos técnicos, socioeconômicos e agroindustriais" (ALVES, 1997) também contribuiu para a difusão de tecnologia da produção em todo o País. A partir da década de 1990, surgiram novos polos de produção de banana irrigada no Vale do São Francisco, como os projetos Jaíba, Gorutuba e Formoso, nos Estados de Minas Gerais e Bahia. Também naquela década, foi desenvolvido um grande trabalho na melhoria do manejo pós-colheita da banana, em Santa Catarina, São Paulo e Minas Gerais. Ainda na década de 1990, a Epagri iniciou uma série de 15 cursos para técnicos e de 54 cursos de profissionalização de bananicultores, treinando mais de cento e cinquenta agrônomos e técnicos agrícolas, e mais de mil produtores, de Santa Catarina e de outros nove estados brasileiros, nas mais modernas técnicas de produção e manejo pós-colheita da banana. Nas duas últimas décadas, floresceram as organizações de bananicultores que, através de seus técnicos, promovem a difusão tecnológica para este cultivo. $\mathrm{Na}$ última década, a disseminação da "sigatoka-negra" em quase todo o território nacional, em lugar de ser um grande desastre, contribuiu para a melhoria das plantações, pois exigiu a adoção de práticas eficientes de controle genético, cultural e químico, e de sistemas de mitigação de risco de disseminação da doença. Assim, no Estado de São Paulo, por exemplo, apesar de uma pequena redução da área cultivada, houve a manutenção da produção estadual, devido ao aumento da produtividade (MORAES et al., 2010). Neste trabalho, são apresentados dados estatísticos e são descritas técnicas de cultivo atualmente disponíveis para a bananicultura brasileira. 


\section{EVOLUÇÃO DA BANANICULTURA} BRASILEIRA

Até pouco tempo atrás, as estatísticas da produção brasileira de banana eram dadas em mil cachos, não se considerando o peso destes cachos. Isto fez com que se tornasse impossível uma análise da evolução da produção e produtividade da cultura da bananeira desde os tempos mais remotos. Em Santa Catarina, dispõe-se de dados em toneladas a partir de 1985, quando a produção estadual foi de 312.877 toneladas, e a produtividade média anual foi de $14.808 \mathrm{~kg}$ por hectare. Levando-se em conta que, em 2009, a produção estadual foi de 670.245 toneladas, e a produtividade média do ano foi de $20.700 \mathrm{~kg}$, estima-se que, no período, houve uma evolução de $114 \%$ na produção e de $31 \%$ na produtividade estadual. Porém, nas décadas de 1970 e 1980, a bananicultura já vivia um processo de evolução tecnológica. Dados extraoficiais dão conta de que, em 1980, a produtividade média estadual era de aproximadamente onze toneladas e que, em 1975, era inferior a nove toneladas por hectare. Este fato ocorreu em quase todo o País.

Aárea cultivada com bananeiras no Brasil, nos últimos anos, é de cerca de 500.000 hectares. A produção brasileira atingiu 6.972 mil toneladas, na safra de 2006/2007, o que colocou o País na quarta posição entre os maiores produtores mundiais de banana. A produtividade média anual brasileira, naquela safra, foi de $13.702 \mathrm{~kg}$ por hectare (EPAGRI/CEPA, 2009). Nos últimos anos, os estados líderes na produção brasileira de banana, foram, pela ordem: Bahia, São Paulo, Santa Catarina, Minas Gerais e Pará.

Embora o Brasil produza em torno de 8\% da produção mundial de banana, o País é responsável por apenas $1 \%$ das exportações mundiais do produto. A produção brasileira de bananas é quase que totalmente dirigida ao mercado interno, devido à nossa grande população e ao elevado consumo per cápita nacional (MOREIRA; CORDEIRO, 2006). Com isso, o País não desenvolveu boas práticas de manejo e conservação pós-colheita exigidas para transporte ao mercado externo, como fizeram os países tradicionalmente exportadores do produto. Em 1930, as exportações brasileiras ultrapassavam os $10 \%$ da produção nacional, ou seja, mais de sete milhões de cachos, de um total de 59 milhões de cachos produzidos no País (SCHMIDT, 1934). Com o tempo, nossas exportações caíram para aproximadamente $1,5 \%$ da banana produzida no País até que, em 2002, o Brasil voltou a exportar um grande volume da fruta, atingindo $4 \%$ da produção nacional, com 241.038 toneladas, caindo nos anos seguintes para 220.771 e 188.087 toneladas. Em 2005, quando nossas exportações de banana atingiram 212.176 toneladas, estes números representaram cerca de 3\% das 6.702 .760 toneladas produzidas naquela safra (CORDEIRO; MOREIRA, 2006), caindo em seguida. Até 1997, o Estado de São Paulo liderou as exportações brasileiras de banana para os países platinos, seguido de Santa Catarina e do Rio Grande do Sul. Naquele ano, iniciaram-se as exportações do Rio Grande do Norte para a Europa, que passou a ocupar a terceira posição até o ano de 1999, e a segunda posição a partir de 2000. Desde 1998, Santa Catarina lidera as exportações brasileiras.

Outra razão para o baixo uso de cuidados na pós-colheita no Brasil é que, com exceção dos Estados de São Paulo, Paraná e Santa Catarina, onde predominam os cultivos de bananeiras do subgrupo Cavendish, a maior parte da produção nacional é de bananas do subgrupo Prata, preferidas pela maior parte dos consumidores brasileiros e mais resistentes aos maus tratos em pós-colheita.

A evolução da bananicultura brasileira foi possível em virtude dos progressos obtidos no que se refere à disponibilidade de material genético diversificado, à disponibilidade de mudas sadias e de boa qualidade genética, às práticas culturais de manejo pré e pós-colheita, às técnicas fitossanitárias desenvolvidas, às técnicas de nutrição e de irrigação, e à melhoria do nível técnico e organizacional do bananicultor brasileiro.

\section{RECURSOSGENÉTICOSDISPONÍVEIS}

Como supõem Moreira e Cordeiro (2006), no início, a bananicultura brasileira contava com duas variedades, a Branca e a Pacova. Destas variedades, originaram-se, por mutação natural, novas variedades. A 'Branca' originou todas as variedades do subgrupo Prata (MOREIRA; CORDEIRO, 2006), de forma direta, como no caso da 'Prata', da 'Prata-Anã' ('Enxerto') e da 'SCS451 Catarina', ou de forma indireta, como no caso da 'Pacovan' e da 'Prata-Gorutuba'. Durante os anos do Brasil Colônia, do Império e da República, muitas outras variedades foram introduzidas no Brasil, como 'Maçã', a 'Figo', a 'Ouro' e a Nanica, que aqui originou por mutação, de forma direta ou indireta, as variedades brasileiras do subgrupo Cavendish (MOREIRA; CORDEIRO, 2006), como a 'Nanicão', a 'Caturrão', a 'Nanicão-Jangada', a 'Salta-do-Cacho', a 'Nanicão IAC 2001' e a 'SCS452 Corupá'. No século passado, foram introduzidas novas variedades do subgrupo Cavendish, como a Willians e a Grande-Naine e outras como a Gross Michel e a Mysore, com os objetivos de aumentar a produtividade dos bananais, de diversificar 
nosso material genético ou de enfrentar problemas fitossanitários. A partir de 1975, a Embrapa iniciou um grande programa de melhoramento genético por hibridação. Com isso, centenas de variedades foram introduzidas dos centros de origem da bananeira e de outros países, especialmente de programas de melhoramento, como o da FHIA, de Honduras. Todo esse material genético foi introduzido com o objetivo principal de obter fontes de resistência às principais doenças da cultura, como o "mal-do-panamá", a "sigatoka-amarela" e, especialmente, a "sigatoka-negra". Alguns destes materiais foram recomendados em algumas regiões brasileiras (CORDEIRO; MOREIRA, 2006), como a 'Thap Maeo', a 'Caipira' ('Yangambi'), a 'Prata-Baby' ('Nam'), a 'Fhia Maravilha' ('FHIA-01'), a 'FHIA 18', a 'FHIA21', a 'Prata-Zulu' ('Pisang Awak'), a 'Prata-Graúda' (SH36-40) e a 'Bucanera'. Um material mutante de 'Thap Maeo' foi selecionado pela Embrapa, em Manaus, originando a cultivar Conquista. Outros materiais foram utilizados em hibridações com as cultivares Pacovan, Prata-Anã, Prata, Prata São Tomé e Yangambi, no programa de melhoramento genético da Embrapa (CORDEIRO; MOREIRA, 2006), originando as variedades 'Pioneira', 'BRS Pacovan Ken' ('Prata Ken'), a 'BRS Preciosa', 'BRS Caprichosa', 'BRS Garantida', 'BRS Japira', 'BRS Vitória', 'BRS Tropical' e 'BRS Princesa'. Com a entrada da "sigatoka-negra" no território nacional, algumas destas cultivares resistentes àquela doença possibilitaram a sobrevivência da bananicultura na Amazônia (GASPAROTTO; PEREIRA, 2010) e em outras regiões onde o controle químico da doença é inviável. Resultados práticos do melhoramento genético da bananeira são apresentados por Silva et al. (2010).

\section{MUDAS MICROPROPAGADAS}

A partir da década de 1980, como ocorreu em diversos países produtores de banana, iniciou-se no Brasil o uso de mudas micropropagadas. Com isto, foi possível implantar rapidamente novos bananais nas regiões tradicionalmente produtoras e em novas regiões de cultivo, com mudas fáceis de transportar e com qualidade genética e sanitária certificadas. Assim, diversos laboratórios instalaram-se no País, visando a abastecer a demanda por mudas de qualidade e das cultivares mais recomendadas para cultivo.

\section{PRÁTICAS DE MANEJO CULTURAL}

Nas publicações de Alves (1997), Lichtemberg (2007b), Moreira (1999) e Rodrigues (2010), entre outras, são descritas práticas culturais disponíveis para o cultivo da bananeira nas diversas regiões do Brasil, desde antes do plantio até a colheita do cacho. Esses conhecimentos têm permitido a obtenção de elevadas produtividades, em plantações das diferentes cultivares e em diferentes condições edafoclimáticas do País. A escolha do local, da densidade de plantio e do arranjo espacial das plantas mais adequado a cada cultivar de bananeira e a cada região pode ser decisivo no sucesso da atividade. Porém, a partir da implantação do bananal, os tratos culturais considerados a seguir permitem a sanidade e a produtividade da cultura.

Controle ou manejo de espécies vegetais espontâneas - o manejo de plantas invasoras na plantação é mais importante nos primeiros meses de cultivo, podendo ser feito por métodos mecânicos (capinas e roçadas) ou químicos (uso de herbicidas registrados para bananicultura). Também são usados alguns métodos de controle cultural, como densidade de plantio, cobertura morta e cobertura vegetal, integrados aos métodos mecânicos e químicos.

Desbaste - é o trato cultural utilizado para manter a densidade do bananal, eliminando o excesso de filhotes da bananeira e selecionando apenas um filhote bem localizado e vigoroso, por geração. A cada geração, um novo filhote é selecionado. A posição do filhote seguidor selecionado é essencial para a manutenção do arranjo espacial, para a penetração uniforme da luz no bananal e para a facilidade de execução de outros tratos culturais, inclusive da colheita. Para tal, todos os filhotes selecionados devem estar orientados aproximadamente no mesmo sentido em relação à sua planta-"mãe", ou seja, no sentido de "caminhamento" do bananal. Como nem sempre se dispõe de um filhote seguidor vigoroso no local desejado, deve-se priorizar o vigor, porém nunca localizado a mais de $90^{\circ}$ da posição desejada, pois aquela característica é a garantia da manutenção do vigor e da produtividade do bananal. Deve-se estar atento para não confundir vigor com altura do filhote, pois isto pode levar à seleção de plantas variantes de porte mais alto do que a cultivar explorada. Para a eliminação dos filhotes indesejados, diferentes ferramentas podem ser utilizadas, tais como: "lurdinha", facão, foice, penado e enxada. A "lurdinha" é usada para complementar o corte com o facão, foice ou penado, para eliminar a gema apical do filhote, evitando a rebrota do filhote. As demais ferramentas podem ser usadas isoladamente, apenas cortando os filhotes, o que exige repasses, para eliminar rebrotes.

Desfolha - é um dos tratos culturais mais importantes para a sanidade do bananal, que consiste na eliminação de folhas não funcionais ou indesejadas 
da bananeira. As folhas secas, amarelas e dobradas no pecíolo, por não contribuírem fisiologicamente, devem ser eliminadas periodicamente dos bananais. $\mathrm{O}$ mesmo deve ser feito com folhas que apresentem sintomas de "sigatoka" ou de outras doenças fúngicas, além daquelas que deformem ou firam os frutos. O corte deve ser feito de baixo para cima, rente ao pseudocaule, utilizando facão, penado, foice bifurcada, podão tipo espátula ou podão bicudo. As áreas de folhas, com sintomas de doenças fúngicas, devem ser estirpadas, sem a eliminação da mesma. Essa operação é denominada "cirurgia", e a ferramenta mais adequada para sua execução é o podão tipo espátula. No controle integrado da "sigatoka", é recomendada a execução semanal da cirurgia, o que ajuda a baixar o potencial de inóculo da doença. A desfolha aumenta a luminosidade e o arejamento do bananal, acelera $o$ desenvolvimento dos filhos, facilita a execução de outras práticas culturais, reduz a ocorrência de pragas e doenças, e melhora a qualidade dos frutos.

Escoramento e amarrio das plantas - A quebra e a queda das bananeiras, causadas por ventos ou pelo peso do cacho, são responsáveis por grandes prejuízos neste cultivo. Quando o problema ocorre em plantas com cachos imaturos, a perda dos frutos é total. Quando ocorre em plantas com cachos já desenvolvidos, a qualidade do fruto é depreciada por machucaduras causadas no seu choque com o solo. Para evitar estas perdas, foram desenvolvidos métodos de escoramento, com uma ou duas varas de bambu ou outro material disponível. Uma extremidade da vara é enterrada superficialmente no solo, para fixá-la, e a outra é espetada ou apoiada na parte superior do pseudocaule, o mais próximo possível do ponto de lançamento do cacho. Como a eficiência, o custo e a disponibilidade de bambu e outros vegetais se tornaram impedimentos ao uso desta prática, diversos materiais foram estudados e aprovados para amarrar as plantas. Assim, atualmente, são usados fitilhos plásticos, cintas plásticas, cordas de náilon, cordas de sisal, cordas de casca de piaçava e outros materiais para manter as plantas em pé. Os fitilhos e cordas para o escoramento não podem esticar e devem resistir à insolação e à umidade. $\mathrm{O}$ escoramento com corda é feito amarrando-se a planta que se quer escorar na altura da roseta foliar, tensionando e prendendo a corda na base do pseudocaule de uma planta vizinha com um nó simples, fixo e não corrediço. O ângulo ideal para o escoramento com cordas é de 45 a 65 graus, o que permite suportar bem o peso do cacho. A bananeira que serve de escora deve, também, estar com cacho ou próximo a lançá-lo, ou, ainda, ter sido recém-colhida. As plantas são atadas no sentido oposto à inclinação do pseudocaule, ou seja, do lado oposto ao do cacho.

Eliminação de restos florais - Em algumas cultivares de banana, os restos florais são persistentes, exigindo sua retirada da extremidade dos frutos. Em algumas cultivares, como a Pacovan, Maçã, Prata, Prata-Anã, Branca, entre outras, a queda dos restos florais ocorre naturalmente. Nas cultivares do subgrupo Cavendish, os restos florais são mais persistentes, estando presentes até nas frutas em ponto de colheita. Na cultivar Nanica, os restos florais são extremamente persistentes. A eliminação dos restos florais é denominada "despistilagem", pois o pistilo é a parte da flor que mais persiste na extremidade dos frutos. A "despistilagem” é feita com diversos objetivos, como: melhorar o aspecto e a forma do fruto, reduzir a incidência da "traça-da-banana", da antracnose e da "ponta-de-charuto" e reduzir ferimentos durante o transporte.

Eliminação da inflorescência masculina Após a abertura das pencas de banana, na raque masculina, continua a abertura de pencas de flores masculinas, até a época da colheita, na maioria das cultivares. Com isto, o cacho da bananeira desenvolve o chamado "rabo" (raque masculina). Com o objetivo de aproveitar os nutrientes gastos no desenvolvimento do "rabo", para o desenvolvimento dos frutos, é recomendada a eliminação do "coração" ou "mangará" do cacho logo após a abertura das pencas. Normalmente, recomenda-se eliminar o "coração" quando este se encontra acerca de 10 centímetros da última penca do cacho. Nas cultivares do subgrupo Cavendish, essa prática permite um ganho de peso do cacho de cerca de $5 \%$, em média. A eliminação ou "poda" do "coração" é feita de preferência pela quebra manual da raque masculina. Em plantas altas, quando não se usam escadas, a poda pode ser feita com foices, podão tipo espátula ou com ferramentas especiais de cabo longo.

Eliminação de pencas - Na comercialização da banana, normalmente, as pencas inferiores do cacho, por apresentarem frutas muito pequenas, são desclassificadas e descartadas. Essas pencas, durante o desenvolvimento do cacho, concorrem com as demais na utilização das reservas acumuladas e dos nutrientes absorvidos pela planta. A eliminação dessas pencas, logo após sua abertura, permite que os frutos das pencas remanescentes do cacho se desenvolvam melhor, alcançando maior comprimento e diâmetro. No Brasil, pelo fato de o mercado aceitar frutas de tamanho pequeno, normalmente, recomenda-se podar apenas a "falsa penca" ou esta mais a última penca. A primeira penca também pode ser podada, quando malformada (poucos frutos) ou deformada. Nos bananais destinados à exportação para merca- 
dos exigentes quanto ao tamanho dos frutos, muitas vezes, faz-se necessária a poda da falsa penca mais duas a três pencas inferiores. Na prática, podam-se as pencas que não são aceitas no mercado ao qual se destina a produção.

Proteção do cacho com bolsas - Para este fim, são usados sacos de polietileno de diversas colorações e níveis de transparência, e sacos de TNT e de papel kraft. De forma geral, têm-se citados como vantagens do ensacamento dos cachos, em qualquer condição climática, os seguintes aspectos quantitativos e qualitativos: a) aumento do peso dos cachos; b) produção de frutos mais longos; c) produção de frutos com maior diâmetro; d) encurtamento do período da floração à colheita; e) produção de frutos com melhor coloração e maior brilho e suavidade da casca; f) redução de danos físicos causados pela abrasão de folhas, deposição de poeira e ação de frio, ventos e de granizo; g) redução de danos de pragas e doenças que depreciam a aparência da casca dos frutos; h) proteção dos cachos contra a presença de ninhos de aves e roedores; e i) proteção contra a deposição de produtos químicos nos cachos, especialmente de óleo mineral e fungicidas quando as pulverizações são feitas com atomizadores costais. Quanto à época de colocação do saco, recomendam-se dois estádios de desenvolvimento do cacho. Os melhores resultados são obtidos quando a execução da prática é mais precoce. Desta forma, o ensacamento das inflorescências pendentes, mas sem pencas abertas, é o ideal. Além disso, nesta época, a execução da prática é mais fácil. Por outro lado, este procedimento exige duas passadas por semana por todas as plantas, para ensacar as inflorescências antes que elas se abram e para eliminar as brácteas que se vão soltando ao abrir das pencas e que ficam presas nos sacos. Outra época recomendada é logo após a completa abertura das pencas, podendo coincidir com a época da eliminação do "coração", das pencas indesejadas e dos restos florais.

Outros tratos culturais - Recomendações técnicas para o desvio de cachos e filhotes, manejo do pseudocaule após a colheita, controle de ventos e outras práticas de manejo do bananal e do cacho também são descritas nos textos de Alves (1997), Lichtemberg (2007b), Moreira (1999) e Rodrigues (2010).

\section{CONTROLE DE PRAGAS E DOENÇAS}

Com relação ao controle de pragas e doenças da bananeira no Brasil, ocorreu um grande progresso, com relação ao controle integrado das pragas e doenças do cacho, da "broca-do-rizoma", das doenças de pós-colheita, da "sigatoka" e de outras doenças foliares. Porém, pouco progresso se fez no controle do "mal-do-panamá", com exceção do registro de novas cultivares resistentes à doença. Com relação à "sigatoka-negra", cultivares resistentes, como BRS Caprichosa, BRS Conquista, BRS Garantida, BRS Japira, BRS Pacovan Ken, BRS Preciosa, BRS Vitória, Caipira, FHIA 01, FHIA 18, FHIA 20, FHIA 21, Figo-Cinza, Ouro, pelipita e Thap Maeo permitem o convívio com a doença, mesmo em ambientes favoráveis à doença (GASPAROTTO; PEREIRA, 2010). Após o ingresso da "sigatoka-negra" no País, métodos de controle integrado da doença evoluíram bastante, como no caso de sistemas de controle por pré-aviso biológico adotados em algumas regiões do País (HINZ, 2010; MORAES et al., 2010). Um novo problema da bananicultura brasileira é a virose BSV, já presente no País há décadas na cultivar Mysore, sem se propagar para plantações de outras cultivares. Com a importação de mudas de cultivares do subgrupo Cavendish, porém, essa enfermidade tornou-se um grave problema no Sul e Sudeste do Brasil.

Os mais recentes avanços no controle de pragas e doenças da bananeira podem ser consultados nos textos de Alves (1997), Dias (2008), Cordeiro (2008), Fancelli \& Mesquita (2008), Gasparotto e Pereira (2010), Hinz (2007 e 2010), Milanez (2007 e 2010), Moraes et al. (2010), Moreira (1999) e Ventura e Hinz (2002).

\section{NUTRIÇÃO, ADUBAÇ̃̃O E IRRIGAÇÃO DOS BANANAIS}

A bananeira é uma planta herbácea de rápido crescimento e de grande porte, que chega a produzir mais de 300 toneladas de matéria fresca por hectare, por safra. Assim, é uma cultura que consome altos volumes de água e de nutrientes. Dos nutrientes absorvidos, a maior parte retorna ao solo e é reciclada. Mesmo assim, é alta a necessidade de adubação, para repor a quantidade de nutrientes exportada pelas colheitas e as perdas no ciclo dos nutrientes no solo. Como exemplo, para uma produção de 50 toneladas de banana, um hectare de bananeiras necessitaria absorver $1.500 \mathrm{~kg}$ de potássio, nutriente mais consumido pela planta. Devido à evapotranspiração da cultura, uma bananeira pode consumir cerca de 40 litros de água por dia. Assim, o consumo diário de água em um bananal pode alcançar facilmente uma lâmina de $4 \mathrm{~mm}$. Com a grande variação das condições edafoclimáticas das diversas regiões produtoras de banana do Brasil, talvez as áreas da nutrição, da adubação e da irrigação sejam as mais carentes de informações técnicas, para a cultura da bananeira. Assim mesmo, informações gerais ou regionaliza- 
das, geradas ou adaptadas no Brasil, são descritas em Alves (1997), Borges e Silva (2010), Coelho et al. (2008), Costa et al. (2008), Malburg (2007), Mendonça et al. (2006), Moreira (1999) e Teixeira (2010).

\section{MANEJO PÓS-COLHEITA}

O grande problema da bananicultura brasilei$\mathrm{ra}$, no que se refere à qualidade da fruta, reside no manejo do produto a partir da colheita. Nessa fase, ocorrem vários danos que prejudicam a aparência do produto. A falta de cuidados no manejo pós-colheita é responsável pela desvalorização da banana no mercado interno e pela perda de oportunidades de exportação da fruta brasileira. Principalmente a partir da década de 90, com a maior demanda do mercado por frutos de qualidade, algumas regiões brasileiras, como o litoral de Santa Catarina, o Vale do Ribeira, o Planalto Paulista, o norte de Minas Gerais e o Vale do Açu (RN) já apresentavam uma evolução no manejo pós-colheita da banana. Porém, muito ainda necessitava e ainda necessita ser melhorado. Atualmente, a operação de colheita já é feita em equipes e já se adotam alguns cuidados nos traslados da fruta, no processo de embalagem e no transporte para o mercado. As técnicas de pós-colheita disponíveis atualmente no Brasil são descritas nos textos de Alves (1997), Lichtemberg (2007a), Lichtemberg e Hinz (2010), Lichtemberg e Pereira (2010), Lichtemberg et al. (2008) e Moreira (1999).

\section{CONCLUSÕES}

Ocorreu grande evolução na bananicultura brasileira nas últimas décadas, devido à geração, adaptação e difusão de tecnologia, à melhoria na organização dos bananicultores, à abertura de polos de bananicultura irrigada e à maior exigência do mercado nacional.

As áreas mais carentes de conhecimento tecnológico são as áreas de nutrição, adubação, irrigação, fitossanidade e a do manejo e conservação pós-colheita da fruta.

A falta de cuidados em pós-colheita é a principal responsável pela baixa qualidade da fruta ofertada na maioria dos mercados brasileiros.

\section{REFERÊNCIAS}

ALVES, E. J. (Org.). A cultura da banana: aspectos técnicos, socioeconômicos e agroindustriais. Brasília: Embrapa-SPI, 1997. 585p.
BORGES, A. L.; SILVA, J. T. A. Adubação e nutrição da bananeira. In: SIMPÓSIO BRASILEIRO SOBRE BANANICULTURA, 7., 2010, Registro. Anais... Registro: SBF/APTA-SP/ABAVAR, 2010. p. 14-36.

COELHO, E. F.; BORGES, A. L.; ALVES, M. S.; COSTA, E. L. Fertirrigação em bananeira. In: SIMPÓSIO NORTE-MINEIRO SOBRE A CULTURA DA BANANA, 2., 2008, Nova Porteirinha. Anais... Nova Porteirinha: EPAMIG/CTNM, 2008. CD-ROM

CORDEIRO, Z. J. M. Sigatoka-amarela da bananeira no Norte de Minas Gerais. In: SIMPÓSIO NORTE-MINEIRO SOBRE A CULTURA DA BANANA, 2., 2008, Nova Porteirinha. Anais... Nova Porteirinha: EPAMIG/CTNM, 2008.. CD-ROM

CORDEIRO, Z. M.; MOREIRA, R. S. A bananicultura brasileira. In: REUNIÃO INTERNACIONAL DA ACORBAT, 17., 2006, Joinville. Anais... Joinville: ACORBAT/ACAFRUTA, 2006. v.1, p. 36-47.

COSTA, E. L.; COELHO, E. F.; SIMÃO, F. R.; COELHO FILHO, M. A.; OLIVEIRA, P. M. Irrigação da bananeira. In: SIMPÓSIO NORTE-MINEIRO SOBRE A CULTURA DA BANANA, 2., 2008, Nova Porteirinha. Anais... Nova Porteirinha: EPAMIG/ CTNM, 2008. CD-ROM

DIAS, M. S. C. Mal-do-panamá da bananeira. In: SIMPÓSIO NORTE-MINEIRO SOBRE A CULTURA DA BANANA, 2., 2008, Nova Porteirinha. Anais... Nova Porteirinha: EPAMIG/CTNM, 2008. CD-ROM

FANCELLI, M.; MESQUITA, A. L. M. Manejo de pragas da bananeira. In: SIMPÓSIO NORTE-MINEIRO SOBRE A CULTURA DA BANANA, 2., 2008, Nova Porteirinha. Anais... Nova Porteirinha: EPAMIG/CTNM, 2008. CD-ROM

GASPAROTTO, L.; PEREIRA, J. C. R. Sigatoka-negra: desafio para a bananicultura brasileira. In: SIMPÓSIO BRASILEIRO SOBRE BANANICULTURA, 7. 2010, Registro. Anais... Registro: SBF/ APTA-SP/ABAVAR, 2010. p. 327-335.

HINZ, R. H. Doenças da bananeira. In: CURSO DE BANANICULTURA, 15., 2007, Itajaí. Palestras... Itajaí: Epagri, 2007. p. 121-151. 
HINZ, R. H. Convivência com a sigatoka-negra: situação na Região Sul. In: SIMPÓSIO BRASILEIRO SOBRE BANANICULTURA, 7., 2010, Registro. Anais... Registro: SBF/APTA-SP/ABAVAR, 2010. p. 209-223.

LICHTEMBERG, L. A. Manejo da banana na colheita e em pós-colheita. In: CURSO DE BANANICULTURA, 15., 2007, Itajaí. Palestras... Itajaí: Epagri, 2007a. p. 152-192.

LICHTEMBERG, L. A. Tratos culturais em bananicultura. In: CURSO DE BANANICULTURA, 15., 2007, Itajaí. Palestras... Itajaí: Epagri, 2007 b. p. $53-73$.

LICHTEMBERG, L.A.; HINZ, R. H. Atualidades na colheita e pós-colheita da banana. In: SIMPÓSIO BRASILEIRO SOBRE BANANICULTURA, 7 .. 2010, Registro. Anais... Registro: SBF/APTA-SP/ ABAVAR, 2010. p. 59-99.

LICHTEMBERG, L. A.; PEREIRA, Mirza Carla Normando. Colheita e pós-colheita. In: GASPAROTTO, L.; PEREIRA, J.C.R. (Ed.). A Cultura da bananeira na região Norte do Brasil. Brasília: Embrapa Informação Tecnológica, 2010. p. 289-310.

LICHTEMBERG, L. A.; VILLAS BOAS, E. V. de B.; DIAS, M. S. C. Colheita e pós-colheita da banana. Informe Agropecuário, Belo Horizonte, v. 29, n. 245, p. 92-110. 2008

MALBURG, J. L. Nutrição e adubação da bananeira. In: CURSO DE BANANICULTURA, 15., 2007, Itajaí. Palestras... Itajaí: Epagri, 2007. p. 74-98.

MENDONÇA, J. C.; PENTEADO, L. A. C.; GODOY, L. J. G. Nutrição e adubação da cultura da banana no Vale do Ribeira. In: WORKSHOP SOBRE NUTRIÇÃO E ADUBAÇÃO NA CULTURA DA BANANA, 2006, Pariquera-Açu. Anais... Pariquera-Açu: UNESP, POTAFÓS, APTA, 2006. p. 58-77.

MILANEZ, J. M. Pragas da bananeira. In: CURSO DE BANANICULTURA, 15., 2007, Itajaí. Palestras... Itajaí: Epagri, 2007. p. 99-120.

MILANEZ, J. M. Manejo e controle da broca-da-bananeira. In: SIMPÓSIO BRASILEIRO SOBRE BANANICULTURA, 7., 2010, Registro. Anais... Registro: SBF/APTA-SP/ABAVAR, 2010. p. 264272.
MORAES, W. da S.; PEREIRA, T. G.; CARNEIRO, O. L. G. A situação atual da sigatoka-negra no Sudeste brasileiro. In: SIMPÓSIO BRASILEIRO SOBRE BANANICULTURA, 7., 2010, Registro. Anais... Registro: SBF/APTA-SP/ABAVAR, 2010. p. 43-58.

MOREIRA, R. S. Banana: teoria e prática de cultivo. Campinas: Fundação Cargill, 1987. 335p.

MOREIRA, R. S. Banana: teoria e prática de cultivo. 2.ed. São Paulo: Fundação Cargill, 1999. CD-ROM MOREIRA, R. S.; CORDEIRO, Z. J. M. A história da banana no Brasil. In: REUNIÃO INTERNACIONAL DA ACORBAT, 17., 2006. Joinville. Anais... Joinville: ACORBAT/ACAFRUTA, 2006. v.1, p. 48-82.

RODRIGUES, M. G. V. Tratos Culturais e manejo de restos da bananeira. In: SIMPÓSIO BRASILEIRO SOBRE BANANICULTURA, 7., 2010, Registro. Anais... Registro: SBF/APTA-SP/ABAVAR, 2010. p. 357-386.

SILVA, J. T. A.; Carvalho, J. G. Avaliação nutricional da bananeira Prata-Anã (ABB) sob irrigação no semiárido do Norte de Minas Gerais, pelo método DRIS. Ciência e Agrotecnologia, Lavras, v. 29, n. 4, p. 731-739, 2005.

SILVA, S. O.; GARRUTI, D. S.; ROCHA, H. S.; SANTOS-SEREJO, J. A.; AMORIM, E. P.; LINO, L. S. M. Resultados práticos do melhoramento genético da bananeira. In: SIMPÓSIO BRASILEIRO SOBRE BANANICULTURA, 7., 2010, Registro Anais... Registro: SBF/APTA-SP/ABAVAR, 2010. p. 304-326.

SCHMIDT, C. B. A cultura prática da bananeira Nanica no Litoral Norte Paulista. São Paulo: Secretaria da Agricultura, Indústria e Comércio do Estado de São Paulo, 1934. 186p.

TEIXEIRA, L.A.J. Fertirrigação da bananeira. In: SIMPÓSIO BRASILEIRO SOBRE BANANICULTURA, 7., 2010, Registro. Anais... Registro: SBF/ APTA-SP/ABAVAR, 2010. p. 243-249.

VENTURA, J.A.; HINZ, R.H. Controle das doenças da bananeira. In: ZAMBOLIM, L. et al. (Ed.). Controle de doenças de plantas: fruteiras. Viçosa (MG): Suprema Gráfica e Editora, 2002. v.2, p. 839-937. 